\title{
'Living' theory: a pedagogical framework for process support in networked learning
}

\author{
Philipa Levy* \\ University of Sheffield, UK
}

\begin{abstract}
This paper focuses on the broad outcome of an action research project in which practical theory was developed in the field of networked learning through case-study analysis of learners' experiences and critical evaluation of educational practice. It begins by briefly discussing the pedagogical approach adopted for the case-study course and the action research methodology. It then identifies key dimensions of four interconnected developmental processes-orientation, communication, socialisation and organisation - that were associated with 'learning to learn' in the course's networked environment, and offers a flavour of participants' experiences in relation to these processes. A number of key evaluation issues that arose are highlighted. Finally, the paper presents the broad conceptual framework for the design and facilitation of process support in networked learning that was derived from this research. The framework proposes a strong, explicit focus on support for process as well as domain learning, and progression from tighter to looser design and facilitation structures for process-focused (as well as domain-focused) learning tasks.
\end{abstract}

\section{Introduction}

This paper focuses on an action research project in which practical theory was developed in the field of networked learning, based on case study exploration and evaluation of the experiences of participants on a professional development course for information services staff in higher education. As course designer and one of a number of tutors, I embarked on the research with the aim of improving my understanding of the experience of learning within the networked environment, and the effectiveness of my educational practice in this context. It is beyond the scope of this paper to present the full detail of the case study, as provided in part elsewhere (Levy, 2006a, b), or of the personal learning that arose out of the research. Instead, the purpose here is to highlight the overarching theoretical outcome of the project: a broad conceptual

\footnotetext{
*Department of Information Studies, Regent Court, 211 Portobello Street, University of Sheffield, Sheffield S1 4DP, UK. Email: p.levy@shef.ac.uk
} 
framework for designing, facilitating and evaluating 'process support' in networked learning. The term 'process support' is used specifically in this paper to refer to support for the development of understandings and capabilities related to 'learning to learn' - as distinct from support for domain (or subject) learning.

Research by Jones et al. (2000, p. 19) indicates that networked learning practitioners often claim not to 'fully understand the relationship between their educational designs and their outcomes'. Action research offers a means of exploring and interpreting this relationship, and of developing conceptual models and frameworks that aim to encapsulate new understandings and guide on-going practice. The educational knowledge produced through this process is personal, practical and essentially contextspecific (Grundy, 1982). Theory produced through action research might be thought of as theory-in-process, the dynamic, 'living' theory of professional practice (McNiff et al., 1996). Nevertheless, the 'living' theory of one practitioner may be of relevance to others working in similar contexts with similar values and purposes.

The paper continues by outlining the pedagogical approach adopted for the course and the action research methodology. It then identifies key dimensions of four broad, interconnected developmental processes-orientation, communication, socialisation and organisation - that were associated with 'learning to learn' in the course's networked environment, and offers a flavour of participants' experiences in relation to these processes. A number of key evaluation issues that arose are highlighted. Finally, the paper presents the broad conceptual framework for the design and facilitation of process support in networked learning that was derived from this research. The framework proposes a strong, explicit focus on support for process as well as domain learning, and progression from tighter to looser design and facilitation structures for process-focused (as well as domain-focused) learning tasks.

\section{Pedagogical approach}

The term 'networked learning' is used in this paper expressly to indicate a specific set of pedagogical understandings and commitments within the broader context of e-learning. The design and facilitation of the case-study course was informed by constructivist educational principles and ideas associated with collaborative professional learning in a 'virtual community', as well as by humanistic perspectives on adult and experiential learning. Constructivist perspectives on learning exist across a wide spectrum, embracing more individual-cognitivist and more social-constructivist and social-constructionist epistemologies. On this spectrum, networked learning perspectives incline towards the latter two. Defined broadly as 'learning in which information and communications technology (ICT) is used to promote connections: between one learner and other learners, between learners and tutors, between a learning community and its learning resources' (Jones \& Steeples, 2002, p. 2), networked learning approaches are underpinned strongly by a social conception of learning that emphasises the importance of dialogical and cooperative engagement within a knowledge-building community of practice. 
At the same time, the networked learning perspective is accommodative, arguably, of ideas and practical frameworks - such as Kolb's (1984) framework for experiential learning - that are more closely aligned with cognitivist than with social perspectives on learning. Kolb defines experiential learning as 'the process whereby knowledge is created through the transformation of experience' (1984, p. 38). His learning cycle models experiential learning as a process involving: engagement in a learning activity or experience; critical reflection; analysis and conceptualisation in the light of other perspectives; assessment of implications as regards application to a new situation; and engagement in a further cycle of learning. The model offers a design framework for addressing the process dimensions of personal and group development in networked and other learning contexts, through activities that aim to develop learners' selfawareness and capacity to continuously learn to learn (Weil \& McGill, 1989).

A key challenge in the networked learning context is the question of how to empower learners to engage actively and productively with the range of pedagogical, social, informational and technical resources that are at their disposal, as well as with a learning approach that may well be unfamiliar to them. Using the facilities, tools and resources of the online environment may not be experienced as straightforward. At the same time, the developmental implications for learners of constructivist pedagogies are well known. Progression from disorientation to reorientation through praxis - that is, through critically reflective action that generates personal, practical knowledge about learning - is recognised as part of the process of becoming a 'constructivist' learner (for example, Brookfield, 1986). Drawing on constructivist principles (for example, Grabinger \& Dunlap, 1995), the four key assumptions that underpinned the design of the case-study course were as follows:

- Learning is not limited to the construction of domain knowledge, but also includes a situated process dimension related to the development of meta-cognitive and other practical capabilities associated with learning itself, which contribute to learners' effectiveness in using the resources within their learning environments and in responding flexibly and positively to challenges encountered.

- Learning activities can be conceived as having two, inter-related dimensions: a domain dimension related to subject focus, and a process dimension related to the learner's engagement with the learning approach, environment, resources and tools.

- Process understanding and skills are constructed through situated engagement within specific learning contexts, but appropriate capabilities cannot be assumed to develop automatically; therefore, pedagogical practice that aims to support process as well as domain learning needs to take into consideration the probable support needs of learners and adopt an integrated, contextualised and explicit approach to process support in the design of tasks, and use of resources and tools.

- Novice networked learners in particular might well need support to further develop those personal understandings, strategies and skills that will be of relevance to this approach to learning and to the tools and resources at their disposal.

With these considerations in mind there was a relatively strong, explicit focus on process in the pedagogical design for the case study course. Kolb's (1984) experiential 
learning cycle was used as a broad framework for the design of reflexive, processoriented learning tasks. The course entailed between six to eight hours of distance learning activity for participants (information professionals from UK higher education) over 17 weeks. Its subject-focus was the professional practice of 'networked learner support'; that is, the educational role of the information specialist in the networked environment. The first, two-week unit aimed to introduce participants (all of whom were newcomers to networked learning) to the course's purposes, environment, tools and approach. Then a number of process tasks were embedded into the course, designed to encourage participants to engage reflexively with their own experience as networked learners, and to focus explicitly on further developing understandings and capabilities of relevance to self-managed, networked learning in a practitioner community framework. For example, one exercise was designed to encourage structured reflection on personal assumptions about, and approaches to, learning, and another to explore collaborative learning practices in the course's online environment. The concluding task of each of the course's seven thematic units was a 'closing round' in which participants were invited to reflect on and discuss online their learning experiences during the unit.

Further key activities within course units (which were of either two or three weeks duration) arose out of a combination of individual, small-group and plenary group tasks. These included: information gathering and exchange; tutor-led discussion in a plenary forum; small-group work including case-study analysis and peer review of individual projects; technology experimentation and evaluation; reading; work-based project development; and learning portfolios and journals. The bespoke technical platform was a relatively simple, web-based environment offering an asynchronous bulletin board, synchronous web-based 'chat', access to a text-based multi-user domain, object-oriented (MOO) with a suite of 'virtual seminar rooms', and access to text-based information resources and learning materials. A graphical activity-map illustrating the sequence of tasks and the relationships between them, and providing guidance on each one, was a feature of the sequentially introduced 'home page' for each unit.

\section{Methodology}

In a critique of methodological approaches that are commonly used in networked learning research, Hodgson and Watland (2004, p. 103) suggest that the field will benefit from the adoption of 'methodological perspectives and methods that are commensurate with the values and ideas of networked learning'. This project sought to apply social constructivist values and methods to the action research approach. Guba and Lincoln's model of constructivist inquiry and evaluation (Guba \& Lincoln, 1989; Lincoln, 2001) proposes a qualitative, 'hermeneutic-dialectic' approach that is concerned with (re)constructing and understanding (socially constructed) experiences and conceptions through cycles of dialogical exchange. Their approach was drawn upon to inform the research design, which blended action research with constructivist evaluation (see Levy, 2003). 
In practical terms, the project involved moving through a cycle of research activities within four main phases: planning the action (the course) and the research; taking the action and monitoring and documenting it; (re)constructing and evaluating it as a case; and further developing 'living' theory of practice for networked learning. A combination of online and face-to-face data collection methods were used, including participant observation and online transcript analysis, online dialogues, a post-course participant feedback questionnaire (responded to by all 33 participants), face-to-face research conversations (with 28 participants), peer debriefing with other tutors, reflective dialogue with a 'critical friend' and a personal research journal. All of these sources were drawn upon for the holistic case (re)construction of 'what happened' on the course and for subsequent evaluative exploration of the question 'how should this be interpreted?' in relation to educational objectives, assumptions and strategies.

The case narrative and associated evaluation were 'member-checked' as part of the research validation process. There was a very high degree of consensus within the group of 15 responding participants that the over-arching conceptual model of experiences of participation (see later) was credible and that the case and evaluation provide a fair and meaningful representation of participant perspectives. While it would have been desirable to achieve a higher level of response to member-checking, the group that did respond represented a good cross-section of experiences of the course.

\section{Learning to learn in a networked environment}

The research led to the identification of four over-arching, interconnected developmental processes associated with learning to learn in the course's networked environment. These were broadly defined as follows:

- Orientation - becoming aware of, and positioned in relation to, key features of the learning environment, resources and approach.

- Communication - using computer-mediated communication (CMC) as a means of self-expression and dialogue within the learning environment.

- Socialisation-developing interpersonal connections, relationships and community feeling within the learning environment.

- Organisation - planning, structuring, managing and directing personal and collective engagement with the networked learning environment, resources and tasks.

Positive experiences in these areas contributed to productive engagement with learning tasks and the learning community, while negative experiences placed constraints on this. Developmental progression in all four areas was facilitated by experiential involvement in the learning activity over time combined with opportunities for reflexive engagement with process issues that arose. However, there was considerable variation in the speed and ease of individual engagement within these areas.

Illustrating these themes, Figure 1 presents a simplified conceptual model of experiences of learning to learn on the course as participants moved through a range of structured learning activities (both domain-orientated and process-orientated). The diagram draws attention to the core processes of orientation, communication, 


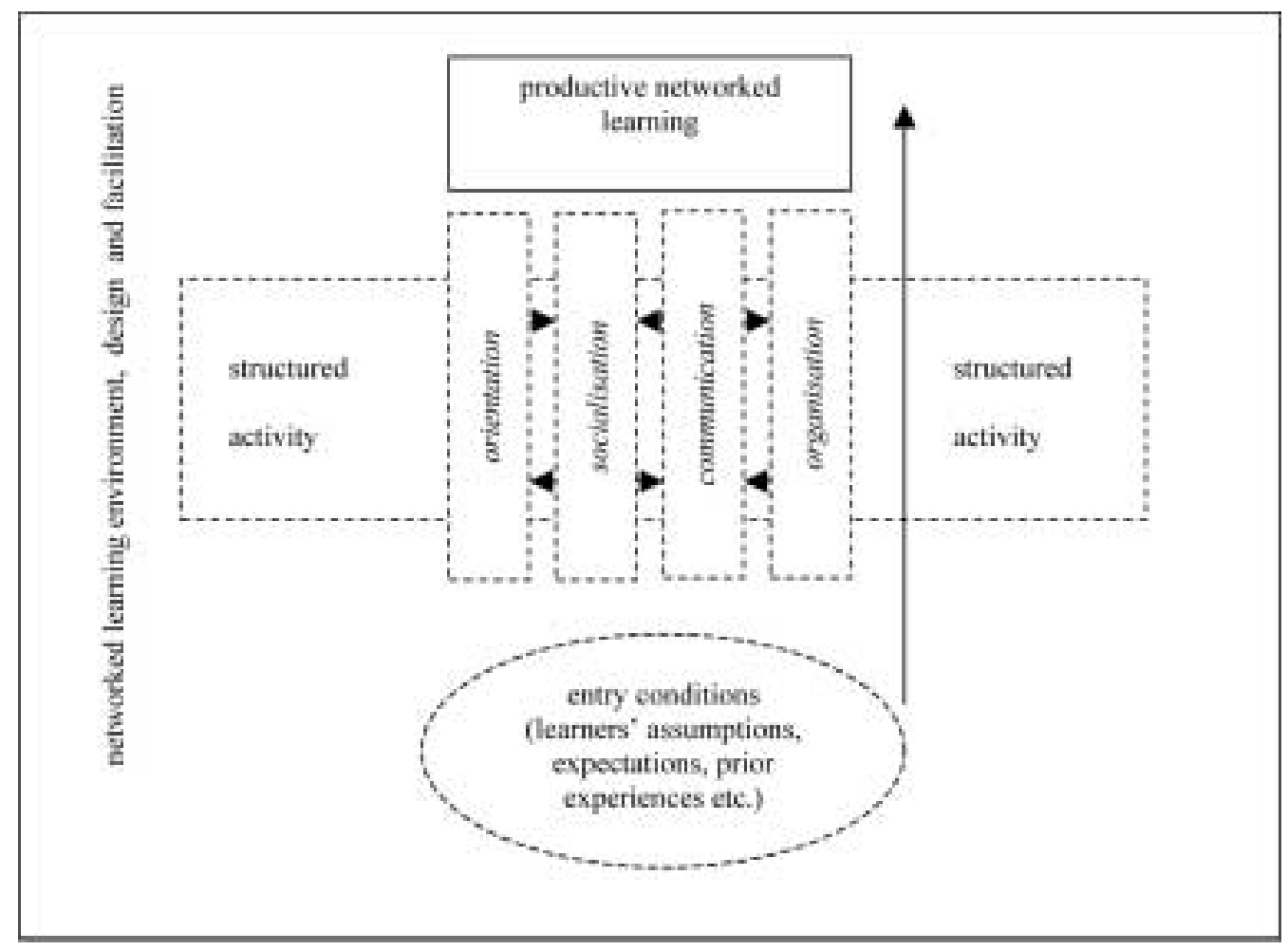

Figure 1. 'Core' developmental processes in networked learning

socialisation and organisation as central within the context of this particular learning environment and the implementation of the design for learning. It shows these processes as parallel and interconnected, and indicates a relationship of mutual influence between experiences in these four areas. For example, experiences of socialisation and communication, as might be expected, were very much interconnected. The developmental dimension of these processes, in terms of perceptions of improved personal awareness, relationships and practices in networked learning over time, is signalled in Figure 1 with the upwards arrow, as is the impact of variations in the 'entry conditions' for individual learners in addition to the impact of design and facilitation factors within the learning environment itself.

The following sections highlight the various dimensions of each 'core' process and some key issues relating to them as they emerged in this environment.

\section{Orientation}

(a) Orientation within the learning space-involving becoming aware of, and positioned within, the structure of the course website and the virtual spaces created by its CMC tools. Most participants needed relatively little time early on to gain a clear overview of the learning environment and resources, and to navigate the 
space easily. The design and usability of the website and CMC tools, the presentation of learning unit overviews and other text and resources, and the quality of technical support were all highly rated in evaluation feedback. However, it took a few participants somewhat longer than others to become fully aware of, and confident about, the structure of the site and the resources and facilities at their disposal. Contrary to expectation, not all participants used their time during the introductory unit to explore the learning space fully when they entered the learning environment, with the result that there were resources that remained undiscovered by them until considerably later on.

(b) Orientation within the information environment - involving becoming aware of, and positioned within, the digital information environment within and beyond the course environment. On the one hand, the extensive scope of the course's Resource Base, with its signposts to a rich, wider landscape of digital resources on the web, was a source of excitement to many participants. On the other hand, it could contribute to a sense of information overload and anxiety. The borderlessness of the environment, combined with the seductions of hypertext, could be experienced as disorienting and in engaging with information resources participants could become distracted from engagement with other tasks. Re-orientation within the information landscape occurred over time, as participants explored what was 'out there' and came to judgements about the quality and relevance of what they encountered in relation to their learning purposes.

(c) Orientation to the pedagogical approach -involving becoming aware of, and engaged with, the nature and practical implications of the pedagogical approach. For some participants, especially those with prior practical experience of selfdirected learning, it proved relatively unproblematic to engage rapidly with, assimilate and act upon information and guidance about the pedagogical approach. For others, this proved to be a much less straightforward and more extended process. It was common in the early weeks to fail to 'take in' early information, guidance and discussion about the approach and tasks. Getting used to the technical features of the environment, intensive activity in some introductory plenary forums and the amount of information available via the Resource Base proved distractions in this respect, and induction tasks relating to exploring the learning approach were experienced as too loosely structured to engage full commitment. More fundamentally, participants often were not in a position immediately to assimilate information about a learning approach that, with its emphasis on self-directedness, collaboration, flexibility of focus in relation to personal learning goals, and critical reflection on process, was both unfamiliar and unexpected. However, they were often reluctant to voice concerns relating to the approach in public forums or via email to tutors.

\section{Communication}

(a) Communicating asynchronously - principally involving using the course's bulletin board system. For some participants, this was experienced as relatively 
straightforward from the outset. As the course progressed, those who became active communicators also became increasingly acclimatised to the dynamics of conferencing and more comfortable with the medium as a means of selfexpression and dialogue. However, many faced a significant learning curve in relation to using asynchronous conferencing, which was experienced as a wholly new form of communication, to support their own and others' learning. In addition, many experienced a high threshold to contributing to seminarstyle discussion in the plenary discussion forum; group size and a commonly perceived need to contribute highly crafted postings were two inhibiting factors here. The threshold was lower within smaller (learning set) groups of four to six people, in which participants often felt freer to adopt a more informal, personal style that was experienced as more in keeping with the dynamics of one-to-one or small group talk in a face-to-face environment. In the light of experience, and shared reflection on experience with tutors and peers, participants' practices and perspectives relating to conferencing commonly changed. Typically, they became less concerned about careful crafting of postings and more aware of the value of informal and conversational, as well as structured and reflective, styles of exchange.

(b) Communicating synchronously - principally involving using the MOO. This was introduced into the learning environment some weeks into the course. There was wide variation in individual responses to the different CMC media, some participants much preferring the more reflective nature of asynchronous interaction over synchronous. Others became enthusiastic users of the MOO, experiencing the real-time interaction as much more akin to face-to-face talk and appreciating the benefits of spontaneity in learning dialogues. The chance to articulate and clarify ideas rapidly, and to gain near-instant feedback, was welcomed, and the medium was found to be valuable for sparking argument and interactive building of ideas.

\section{Socialisation}

(a) Developing connections and relationships-forming one-to-one interpersonal connections and relationships with tutors and peers. As the course progressed, some participants developed a strong sense of interpersonal connection and relationship with others, as mediated through both asynchronous and synchronous interaction. This played an important role in their engagement with the course. Developing interpersonal connection was strongly associated with the experience of sensing the 'social presence' of others. Engagement in real-time interaction via the MOO was often found to be more conducive to this than asynchronous interaction. In general, the strongest and most satisfying interpersonal connections developed within the context of small group interactions in which social as well as task-related interaction became an integral aspect of building dialogical learning relationships.

(b) Developing community - experiencing group or community affiliation within the learning environment. Although not a universal experience, most participants 
experienced a growing sense of involvement in community, or 'groupness' as the course progressed. The sense of community affiliation was fostered in particular through opportunities to identify shared professional identities, experiences and concerns, and also tended to be associated with individuals' position in the exchange network. Those who were most active in exchanging advice, ideas, feedback and support in the context of collaborative learning tasks and dialogical reflection developed a particularly strong sense of belonging, which itself motivated further reciprocal exchange. Unsurprisingly, a sense of affiliation was strongest in relation to the group of people with whom participants experienced the most intensive exchange-for most, their smaller learning set rather than the wider group. The use of real-time communication was perceived to be a key factor in cementing group as well as individual relationships, and fostering a collective sense of group belonging and commitment, in a number of sets.

\section{Organisation}

(a) Managing communication-involving developing practical access and response routines for asynchronous conferencing, and organisational strategies for using synchronous 'chat' effectively. This was one of five areas in which participants often referred to the need to develop personal and collective organisational 'structures' for their learning. Some were especially successful in developing regular patterns of frequent access, with a positive impact on the strength of their engagement (whether as active communicators or not) with course discussion. Some also adopted disciplined response routines that helped them to sustain personal motivation to participate and to keep up with the rapid pace and high volume of traffic in some plenary discussions. Others failed to establish effective, practical routines for accessing and contributing to forums, with a negative impact on their sense of involvement. Some sets established regular (generally weekly) meetings in the MOO, which was found to provide a welcome change of pace and helped to stimulate and sustain group interaction. Following an initial MOO training session, some sets were particularly successful in combining the use of synchronous and asynchronous modes of communication, which were experienced as complementary, in an integrated way.

(b) Managing information - involving developing strategies for engaging with the flow of information generated within the learning environment, including selective reading and storing of especially relevant information in personal portfolios. The need to develop strategies to manage the flow of information was experienced in particular in relation to engaging with the volume of conferencing traffic. Information overload here was a common experience towards the start of the course especially, at which time it was common to start out by attempting to read every posting to the public forums. As threads and themes multiplied many participants became more selective in what they chose to follow.

(c) Managing time-involving allocating time to the networked learning in the context of working and domestic lives. This was a key challenge for many participants. 
Compounding their own problems with time, the pace of the course was generally experienced as too rapid, learning unit time-scales as too short, and collaborative online activities unexpectedly time-consuming, leading to frustrations and some constraints on assimilation of learning.

(d) Managing flexibility-involving imposing personal structure and direction in relation to flexible learning tasks. Some participants responded positively to this from the start, but most felt the need for more externally imposed structure in this respect to begin with, developing a clearer sense of personal direction and tailoring their focus to their developing interests as time went on. 'Managing flexibility' also involved managing the flexible mode of study, in that participants needed to establish a personal study pattern that would enable them to accommodate appropriate asynchronous and synchronous communication routines as well as periods of individual planning and activity. With competing demands on their time, it was common to struggle with the practice, if not the principle, of flexibility as a mode of study; real-time meetings in the MOO, while entailing some sacrifice of personal flexibility, were found to be useful in terms of imposing structure on personal work patterns.

(e) Managing collaboration - involving coordinating and facilitating collaborative activity online, in small, distributed learning groups. Some sets included participants who from the outset were particularly strongly motivated to contribute to coordinating collective activity. However, proactive interventions by tutors in the early stages of the course were critical in establishing the momentum of collaborative work in an unfamiliar environment. As time went on, coordination typically became increasingly shared among group participants. The reflective group review task some way into the course was effective in further enhancing group organisation and processes, helping in the development of better collective understanding and agreement in sets about how to manage collaboration in the online environment in ways that suited their particular context.

\section{Evaluation}

The preceding section has highlighted some key aspects of experiences of acclimatisation (or non-acclimatisation) to an unfamiliar learning environment and approach - a process that entailed a level of frustration and anxiety as well as excitement for many participants as they engaged, individually and collectively, with new conceptions of, and strategies for, professional learning. There are a number of points of similarity between the picture of networked learners' experiences as represented in this case and that afforded by other research (for example, Eastmond, 1995; McConnell, 2000). However, rather than revealing stage-by-stage learner progression through a generic sequence of experiences/practices (Salmon, 2000), the picture that emerged here was of diverse experiences of engagement with interconnected, in-parallel developmental processes. This non-linear perspective on learners' experiences suggests the need for a non-linear, holistic approach to process support. 
From an evaluative perspective, the case study raised the question of the effectiveness of process support strategies in relation to the various dimensions of the four 'core' developmental areas, both at the stage of induction to the learning environment and beyond. Evaluation therefore focused specifically on exploring this question. There was strong consensus among participants that a more extended online induction period at the start of the course would have been welcome. The research suggested a conceptual framework for this, in terms of preliminary scaffolding for the various dimensions of the four key process areas. For example, strategies identified for more extended induction included: more tightly structured initial exploration of the implications of features of the learning design and approach, combined with increased personal contact between individual learners and tutors (orientation); exploitation of multiple communications media and small group formats to encourage early engagement with CMC (communication); group-building activity for learning sets (socialisation); and practical guidance on personal communication discipline and issues related to 'media choice', time management and group coordination (organisation).

The following paragraphs highlight some of the especially salient points that emerged from the process-support evaluation in relation to four key dimensions of designing and facilitating networked learning: task design, socio-technical design, information design and tutoring design/practice. Task design refers to the design of individual, small group and plenary learning tasks, including aspects such as peer feedback and support. Socio-technical design refers to the design of the technical platform for the social environment. Information design refers to the design of the information environment and specific information/learning resources. Tutoring design refers to the strategy for tutoring (e.g. as regards facilitation of collaborative activity) and its implementation in practice, and includes technical support where this is provided in person. These categories emerged from a preliminary cycle of evaluation data analysis and, consequently, were then adopted to structure the evaluation of each process area.

\section{Task design}

The question of structure was perhaps the key issue that arose in relation to the design of both process-focused and domain-focused learning tasks. Research by Jones et al. (2000) has suggested that the matter of how to introduce structure into designs for learning, and how much structure to introduce, are often key issues for networked learning practitioners. These authors contrast 'tight' design structures-reflected in strategies such as detailed task instructions, pre-identified outputs and strict deadlines-with 'loose' structures that offer greater scope for participants to determine the processes, direction and outcomes of their inquiries. The more successful design approaches examined in their research tended to exhibit 'tight initial structures [...] but then allowed relative freedom in a loosely structured environment' (Jones et al., 2000 , p. 26). This action research project pointed to similar conclusions. Tight structure in relation to individual and collaborative tasks, particularly at the start of 
the course, had a positive impact in terms of engagement with core processes; loose structure had a negative impact.

The relatively strong focus on process on the course, in the form of opportunities for critical reflection and dialogue on process issues, was found particularly valuable for the development of 'learning to learn' capabilities. Evaluation confirmed the need for, and value of, providing explicit, structured on-going support for process development beyond an initial 'induction' period, responsively encouraging a reflexive approach to process issues as they emerged and using the experiential learning cycle as a design framework for process activity. The potential to apply the experiential learning cycle more systematically and in a more tightly structured way to the design of process tasks, and the likely benefits of such an approach especially in the earlier stages, emerged as a particularly significant outcome of evaluation of the course. However, there is greater difficulty, in the online as compared with the face-to-face environment, of directing and pacing learners' engagement with a designed sequence of learning tasks. This suggests that e-learning systems that facilitate structured progression through a series of activities with associated outputs, such as the Learning Activity Management System, may prove to offer a useful platform for online approaches that seek to apply the experiential learning cycle as a design framework.

\section{Socio-technical design}

The main issue that arose in relation to the technical design of the social environment was associated with the use of the MOO. As highlighted in the case synopsis, synchronous communication using this medium was shown to have a strong positive impact for many participants for key aspects of communication, socialisation and organisation. Its use in combination with other media supported individual differences in communication styles and preferences, and it enabled exploitation of the value of spontaneity in communication. Like other research, this project suggested that 'synchronous communication [...] contributes much more to community-building than asynchronous communication' (Haythornthwaite et al., 2000, p. 15) and it also highlighted the value of the MOO in relation to managing time, flexibility and collaboration. These considerations suggested that earlier and more embedded use of this (or similar) technology would have had significant process benefits in all of these areas. In the light of the communication and socialisation benefits of the MOO it also seems likely that early use of synchronous CMC would have improved the conditions for dialogue on orientation issues, by providing an additional platform for discussion between peers and with tutors.

\section{Information design}

Issues relating to the provision of information resources arose in relation to supporting aspects of orientation, organisation and socialisation in particular. As illustrated, the extensive Resource Base contributed to information overload early in the course. An alternative approach would have been to expose participants to fewer pre-identified 
resources initially, as the first stage in a step-by-step process towards orientation within the broad 'information landscape' of relevance to their interests. The need for additional guidance materials on aspects of organisation for networked learningsuch as how to manage asynchronous communication routines, and how to divide time between online and offline activity - was also flagged up through the evaluation process. Information design issues relating to supporting socialisation included the identification of enhanced strategies for promoting on-going 'people-networking' through the presentation of dynamic (as opposed to fixed) and more easily searchable personal learner profiles.

\section{Tutoring design/practice}

A range of issues arose from the evaluation of tutoring design and practice in relation to each of the core processes, including for my own practice as a tutor. That there was a need for more intensive personal contact between tutors and learners at the earlier stages of the programme in particular, in order to better support orientation within the learning space and to the approach, has already been highlighted. Another general issue was associated with the role of tutors in supporting socialisation, in terms of willingness to share personal experience and to become actively involved in (and model) exchange of valued community 'resources' such as advice and assistance in informal as well as more formal interactions.

\section{'Living' theory}

The research highlighted themes related to developmental, 'learning to learn', issues in networked learning. It enabled refinement of a conceptual framework for process support in networked learning that is informed by constructivist and experiential learning principles, and validated by empirical inquiry. Figure 2 represents the overarching 'living' theory that was developed through this project in terms of a non-linear framework for the design and facilitation (and, by extension, evaluation) of process support for networked learning.

As illustrated, the framework identifies four broad foci for integrated process support-orientation, communication, socialisation and organisation-within two broad design/action phases: induction and on-going development. The implication is that these foci and phases need to be taken into consideration when applying four underpinning elements of networked learning design and facilitation-identified as task design, socio-technical design, information design and tutoring design/practice. The framework also suggests a strategy of progression from tighter to looser structures in the design and facilitation of both process and domain learning as learners become increasingly acclimatised to their environment and the learning approach. The relationship between the four key process dimensions of networked learning is conceived as in-parallel and interconnected, rather than sequential. This suggests the possibility of a holistic, integrated and flexible pedagogical approach that aims to be sensitive both to individual differences within the learning group in terms of 


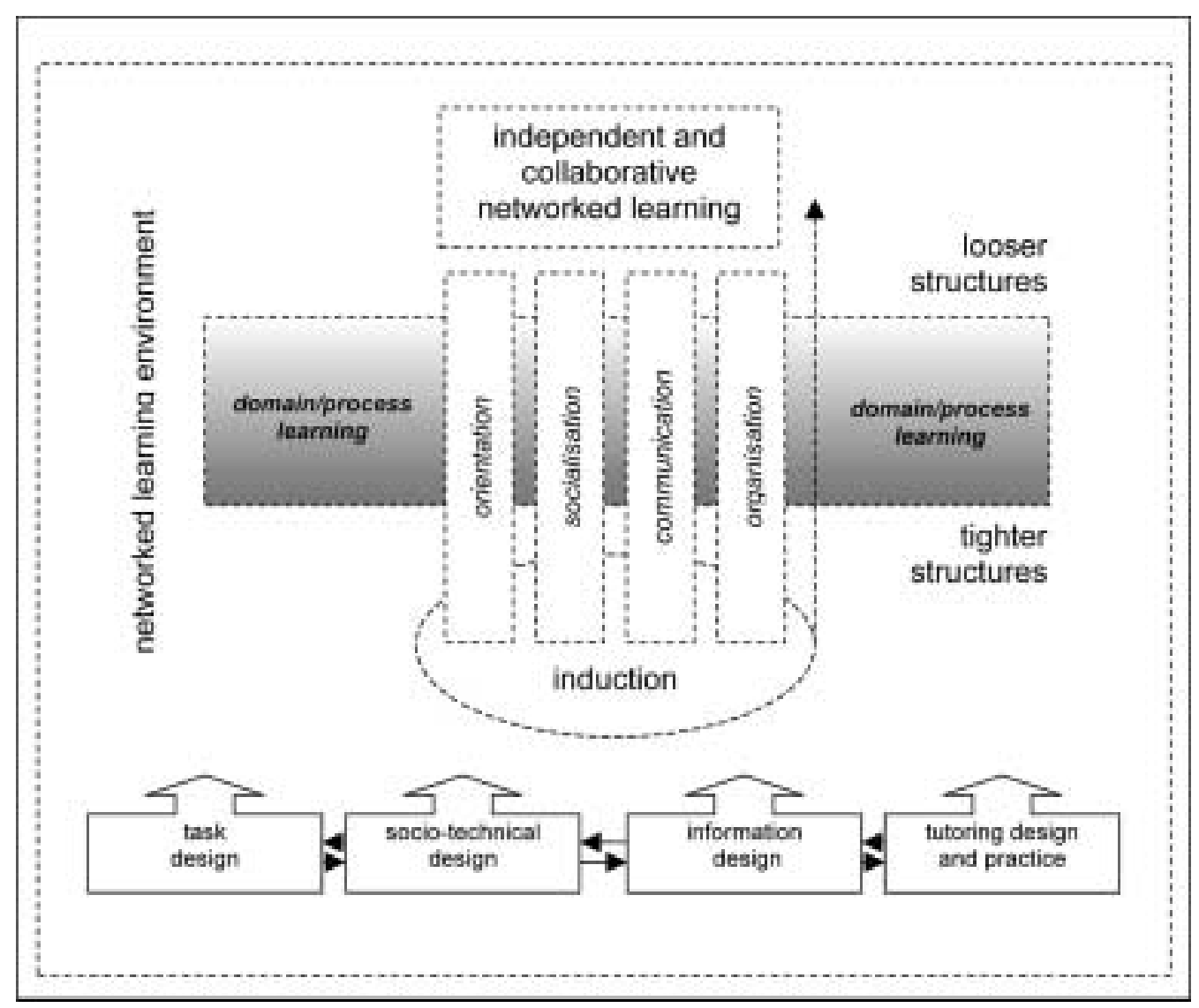

Figure 2. Non-linear framework for process support in networked learning

'readiness' for different aspects of networked learning in a given environment, and to the multi-dimensional character of the overall developmental process at any given point in a networked learner's experience.

In incorporating a strong, explicit focus on process as well as domain activity within the learning environment, the framework reflects a holistic view whereby subject and process domains in learning are conceived as inextricably connected. It also reflects an assumption that initial induction, while important, will not be sufficient to support the developmental process, for newcomers to networked learning, of 'learning to learn' through on-going, situated, collective action. Thus, the framework contextualises explicit 'learning about process' in relation to (increasingly complex) domain learning. Based on this case study research, it suggests that a key part of pedagogical strategy for networked learning will be the design of online tasks and feedback designed to support the construction of reflexive process knowledge about 'constructivist learning' as well as domain knowledge-with the experiential learning cycle providing a useful design framework in this respect. Alexander and Boud (2001, p. 3) have noted that 'learners still learn from experience when online', and this case study 
suggested that the experiential learning design framework can transfer well from faceto-face to online learning environments.

The framework expresses pedagogical intent at a high level of abstraction and generality. Moreover, as a representation of personal, 'living' theory, it aspires neither to all-inclusive representation of process support issues in networked learning nor to universal applicability. Rather, it is offered simply as a working model that is grounded in the specific concerns and circumstances of personal practice and understandings - that is amenable to further testing, refinement and elaboration. A further outcome of this project was a personal checklist of reflection points and flexible 'rules of thumb' for implementing the framework in my continuing practicenot as a fixed blueprint, but as an aide-memoire of issues for consideration when different initiatives are being planned.

\section{Conclusion}

The paper has shown how the move was made from an exploration of networked learners' experience, and a critical evaluation of personal practice, to the refinement of a broad conceptual framework that encapsulates the understandings derived from the action research and that can guide continuing practice and research/evaluation. In highlighting four 'core' process areas and the question of structure in networked learning, the theoretical principles underpinning this framework (or 'living' theory) are assumed, rather than made explicit, in Figure 2. Over recent years, a number of pedagogical frameworks for e-learning have been proposed from constructivist and related perspectives, as reviewed by Mayes and de Freitas (2004). The distinctive element of this framework is in highlighting the interconnection between domain and process learning and in suggesting a non-linear approach to supporting learning to learn in the networked environment, based on experiential learning design and progression from tighter to looser structures for process-focused (as well as domainfocused) learning activity.

\section{References}

Alexander, S. \& Boud, D. (2001) Learners still learn from experience when online, in: J. Stephenson (Ed.) Teaching and learning online (London, Kogan Page).

Brookfield, S. D. (1986) Understanding and facilitating adult learning (Milton Keynes, Open University Press).

Eastmond, D. V. (1995) Alone but together: adult distance study through computer conferencing (Cresskill, NJ, Hampton Press).

Grabinger, S. R. \& Dunlap, J. C. (1995) Rich environments for active learning: a definition, ALT-F, fournal of the Association for Learning Technology, 3(2), 5-34.

Grundy, S. (1982) Three modes of action research, Curriculum Perspectives, 2(3), 23-34.

Guba, E. G. \& Lincoln, Y. S. (1989) Fourth generation evaluation (London, Sage).

Haythornthwaite, C., Kazmer, M. M., Robins, J. \& Shoemaker, S. (2000) Community development among distance learners: temporal and technological dimensions, fournal of Computer-mediated Communication, 6(1). Available online at: http://www.ascusc.org/jcmc/vol6/issue1/haythornthwaite.html (accessed 5 August 2005). 
Hodgson, V. \& Watland, P. (2004) Researching networked management learning, Management Learning, 35(2), 99-116.

Jones, C. \& Steeples, C. (2002) Perspectives and issues in networked learning, in: C. Steeples \& C. Jones (Eds) Networked learning: perspectives and issues (London, Springer-Verlag).

Jones, C., Asensio, M. \& Goodyear, P. (2000) Networked learning in higher education: practitioners' perspectives, ALT-F Fournal of the Association for Learning Technology, 8(2), 18-28.

Kolb, D. (1984) Experiential learning: experience as the source of learning and development (Englewood Cliffs, NJ, Prentice-Hall).

Levy, P. (2003) A methodological framework for practice-based research in networked learning, Instructional Science, 31(1-2), 87-109.

Levy, P. (2006a) 'Learning a different form of communication': experiences of networked learning and reflections on practice. Studies in Continuing Education (Special Issue on Networked Learning), in press.

Levy, P. (2006b) Learning to learn in networked environments: a focus on 'orientation', in: H. S. Ching, P. W. T. Poon \& C. McNaught (Eds) e-Learning and digital publishing (London, Springer).

Lincoln, Y. (2001) Engaging sympathies: relationships between action research and social constructivism, in: P. Reason \& H. Bradbury (Eds) Handbook of action research: participative inquiry and practice (London, Sage).

Mayes, T. \& de Freitas, S. (2004) Review of e-learning theories, frameworks and models. FISC e-learning models desk study. Available online at: www.jisc.ac.uk/uploaded_documents/ Stage\%202\%20Learning\%20Models\%20(Version\%201).pdf (accessed 5 August 2005).

McConnell, D. (2000) Implementing computer supported cooperative learning (2nd edn) (London, Kogan Page).

McNiff, J., Lomax, P. \& Whitehead, J. (1996) You and your action research project (London, Routledge).

Salmon, G. (2000) E-moderating: the key to teaching and learning online, (London, Kogan Page).

Weil, S. W. \& McGill, I. (Eds) (1989) Making sense of experiential learning: diversity in theory and practice (Milton Keynes, Society for Research in Higher Education/Open University Press). 